\title{
Fruit and vegetable intake: change with age across childhood and adolescence
}

\author{
Viviana Albani ${ }^{1 *}$, Laurie T. Butler ${ }^{2}$, W. Bruce Traill ${ }^{3}$ and Orla B. Kennedy ${ }^{4}$ \\ ${ }^{1}$ Institute of Health \& Society and Human Nutrition Research Centre, Newcastle University, Baddiley Clark Building, Newcastle \\ upon Tyne NE2 $4 A X$, UK \\ ${ }^{2}$ School of Psychology and Clinical Language Sciences, University of Reading, Harry Pitt Building, Earley Gate, Reading RG6 6AL, UK \\ ${ }^{3}$ School of Agriculture, Policy and Development, University of Reading, Whiteknights, PO Box 237, Reading RG6 6AR, UK \\ ${ }^{4} H u g h$ Sinclair Nutrition Unit, University of Reading, PO Box 226, Whiteknights, Reading RG6 6AP, UK
}

(Submitted 2 August 2016 - Final revision received 19 December 2016 - Accepted 21 February 2017)

\section{Abstract}

Eating fruit and vegetables (FV) offers important health benefits for children and adolescents, but their average intake is low. To explore if negative trends with age exist as children grow, this study modelled differences in FV consumption from childhood to young adulthood. A pseudo-panel was constructed using years 1-4 (combined) of the Rolling Programme of the UK National Diet and Nutrition Survey (NDNS) (2008/2009-2011/2012). Intake of FV in the NDNS was recorded using 4-d unweighted food diaries. The data consisted of 2131 observations of individuals aged 2-23 years. Age-year-cohort decomposition regression analyses were used to separate age effects from year and cohort effects in the data. Total energy intake was included to account for age differences in overall energy consumption. Fruit intake started to decrease from the age of 7 years for boys and girls, and reached its lowest level during adolescence. By 17 years, boys were consuming 0.93 $(P=0.037)$ less fruit portions compared with the age of 2 years. By 15 years, girls were consuming 0.8 fruit portions less $(P=0 \cdot 053)$. Vegetable intake changed little during childhood and adolescence $(P=0.0834$ and $P=0.843$ for change between 7 and 12 years, boys and girls, respectively). There was unclear evidence of recovery of FV intakes in early adulthood. Efforts to improve FV intake should consider these trends, and focus attention on the factors influencing intake across childhood and adolescence in order to improve the nutritional quality of diets during these periods.

\section{Key words: Fruits: Vegetables: Children: Adolescents: Age trends: Pseudo-panels: Biases}

Consumption of fruit and vegetables (FV) during childhood and adolescence is important for healthy growth, reduction of obesity and reducing future cancer risks ${ }^{(1-4)}$. Nevertheless, national dietary surveys in high-income countries show that large numbers of children and adolescents have FV consumption levels that fall below recommended guidelines, with adolescents at a higher risk for low intake ${ }^{(5-8)}$. The observed differences in intake across age groups may arise from the multiple changes in lifestyle and physical and social environments that take place between childhood and adolescence. For example, previous studies have shown that children start to eat less FV when they go from primary to secondary school ${ }^{(9-11)}$. Given the potential for deterioration of FV intake with children's development, the aim of this study was to explore differences with age in FV intake from childhood to adolescence as a critical step for planning the timing of interventions to ensure adequate nutritional quality of young people's diets ${ }^{(12)}$.

Results from longitudinal studies looking into change with age in FV intake have shown decrease in consumption of fruit at different points in time from childhood to young adulthood, but less clear trends for vegetables. In the context of the US-based Bogalusa Heart Study, Larson et $a l^{(12)}$ observed a decrease in FV intake both in the transition from early to middle adolescence and from middle to late adolescence (approximately the period between 11 and 17 years), whereas Demory-Luce et $a l^{(13)}$, also using data from a regional US cohort, found a significant decrease in fruit and fruit juice intake, but no change in vegetable intake between the ages of 10 and mid-20 years. Similarly, using the frequency of daily FV intake to approximate children's FV consumption, a study looking at three different age cohorts in a semi-urban area of Sweden found a decrease in fruit intake over 2 years (8-10, 11-13 and 14-16 years), but a decrease in vegetable intake only for high-socioeconomic groups $^{(14)}$. A critical assumption in these studies, however, is that cohort and year effects have not influenced the observed trends with age. (Survey) Year effects (e.g. the yearly state of the economy) could have accentuated upward or downward trends in the data of these longitudinal samples, whereas cohort

Abbreviations: FV, fruit and vegetable; NDNS, National Diet and Nutrition Survey.

* Corresponding author: Dr V. Albani, fax +44 191208 6043, email viviana.albani@newcastle.ac.uk 
effects could have introduced bias from looking at only one generation over time; that is, observed patterns with growth would be representative of the studied cohort, but not of older or younger groups ${ }^{(15,16)}$. Controlling for both effects using data from different cohorts is therefore important to identify the true development of FV consumption with age ${ }^{(17)}$.

In addition, studies have so far explored the trajectory of intake from the ages of 8 to 10 years onwards but little is known about the developmental trajectories of FV intake from earlier ages. FV intake could start to change early; for example, as children go through stages of food neophobia, have greater interaction with peers that can influence their preferences, and are more exposed to food cues in the environment (e.g. food marketing $)^{(18,19)}$. If there are negative trends with age in $\mathrm{FV}$ intake, it is important to identify the earliest stage at which intake starts to deteriorate in order to intervene more effectively to improve diets later on.

The aim of this study was to investigate how FV intake changes with age from early childhood until late adolescence using robust methods that address critical confounders in previous studies of cohort and year effects. Differences with age were examined separately for males and females to understand if different risk paths for low FV consumption existed in these groups.

\section{Methods}

\section{Controlling for age, year and cohort effects}

Change in FV consumption over time can be modelled as the sum of age, cohort and time effects ${ }^{1,2(17,20,21)}$. Methodologically, an individual's cohort membership is determined through a linear relationship between age and (survey) year, making it hard to separate these effects ${ }^{(21)}$. Approaches to tackle the identification of age, year and cohort effects in linear models combining the three variables involve imposing constraints on one of the effects, some previous assumptions on the shape of the effects or both ${ }^{(22,23)}$. Deaton ${ }^{(15)}$ proposed a descriptive ageyear-cohort decomposition first applied for the study of economic life-cycle phenomena, in which (i) given sufficiently large sample sizes, indicator variables are used to describe the three effects, avoiding any a priori assumptions about the shape of the effects; (ii) year effects are normalised (set to have a 0 mean and to be devoid of any trend) ${ }^{(24)}$, leaving only the predictable components of age and cohort as explanation of the patterns in the $\mathrm{data}^{3(22)}$. For estimation purposes (see online Supplementary material), the method requires the exclusion of

${ }^{1}$ It is also possible to attempt to recreate the patterns in the data solely through age effects and a time trend. The time trend acts by shifting the average age-based behaviour with the passing of time ${ }^{(15)}$. This is equivalent to assuming constant cohort effects.

${ }^{2}$ The model used also assumes that the effects of age, cohort and time are not influenced by each other, that is there are no interaction (multiplicative) effects. Thus, for example, it is assumed that the developmental processes (the shape of age effects) are not substantially different across cohorts or time ranges, which is usually assumed to be true for short time periods ${ }^{(15,17,23)}$

${ }^{3}$ It is possible to impose the normalisation on the cohort effect or the age effect as opposed to the year effect ${ }^{(24)}$. The choice depends on the objective of the research and the underlying assumptions. For example it may be of interest to study the effect of a policy or a shock (year effect) abstracting the first category in the set of age and cohort indicator variables, and the first two in the case of the normalised year indicator variables.

Construction of a pseudo-panel. The age-year-cohort decomposition described above requires data on more than one age group (cohorts) at any point in time, with repeated observations over time. A panel data set satisfies these conditions because it follows over time the same study participants that belong to different cohorts. In the case of repeated crosssections, surveys are not designed to follow the same individuals in each survey wave, but they provide samples from the same cohort over a period of time using the same sampling method, and the average behaviour of the individuals that belong to a cohort can be estimated for each survey period and used to build a pseudo-panel ${ }^{(15,23,25)}$. Changes in these averages can then be used to explore developmental differences of large groups in the population ${ }^{(20,26)}$. To account for the skewness of food intake data, cohort medians instead of averages were used ${ }^{(15,27)}$. The corresponding equations and a more detailed explanation of the method can be found in the online Supplementary material.

\section{Data}

Data on FV intake between the ages of 2 and 23 years was obtained from the pooled 2008/2009, 2009/2010, 2010/2011 and 2011/2012 waves of the UK National Diet and Nutrition Survey (NDNS). The NDNS collected FV consumption information, including FV from composite dishes ${ }^{4}$, using consecutive 4 -d unweighted food diaries from individuals aged $\geq 1.5$ years living in private households. Data collection took place across all months of the year to control for seasonality in food intake, but in the final pooled sample there was a slight overrepresentation of weekend days ${ }^{(28)}$. Total sample size was 2131 observations. Observations were calibrated using the NDNS weighting variable (pooled sample) when calculating the cohort medians. After estimating the medians for each cohortyear cell the total number of observations for the estimation of the age-year-cohort decomposition model was 175 (online Supplementary Table S1.2).

\section{Measures}

The dependent variables were the estimated cohort medians of daily vegetable portions (maximum of $80 \mathrm{~g} / \mathrm{d}$ of pulses and five times the intake of tomato purée $(\mathrm{g} / \mathrm{d})$ ), total fruit portions (maximum of $150 \mathrm{~g} / \mathrm{d}$ of fruit juice and $160 \mathrm{~g} / \mathrm{d}$ of fruit smoothies, and three times the intake of dried fruits), fruit portions (total fruit portions minus fruit juice) and total FV portions (including fruit juice). The definitions of portions were those used in the NDNS. Age effects were estimated using twenty-two age variables, one for each age between 2 and 23 years. In all, 4 year

from the influence of age ${ }^{(16)}$. The interest here is the developmental path of FV consumption, and age is thus retained as fundamental to the analysis.

${ }^{4}$ Intake from composite dishes takes into account the contribution to the total intake of the food from its use as an ingredient in purchased products or in homemade recipes. 
variables (NDNS waves), and twenty-five cohort dummies ${ }^{5}$ were used for year and cohort effects, respectively. The youngest cohort was composed of those aged 2 years in 2011/2012 and the oldest was composed of those aged 23 years in 2008/2009. Given the age bracket, some cohorts were not observed in some survey waves. Total energy intake from food was measured in $\mathrm{MJ} / \mathrm{d}$.

\section{Estimation strategy}

Linear models of FV intake against age, cohort and normalised year effects were calculated including a set of interaction terms between the age indicator variables and sex to capture differences in age effects between boys and girls. Multivariate energy adjustment was done to control for the potential confounding effect of differences with age in total energy intakev ${ }^{6(29)}$. Heteroscedasticity consistent (HC2) robust standard errors were used to account for the estimated nature of the dependent variable and model heteroscedasticity ${ }^{(30,31)}$. Stata 13 Statistical Software ${ }^{(32)}$ was used for all analyses.

\section{Results}

Fig. 1-3 illustrate, for males and females, the estimated change with age of total vegetable and fruit portions intake. At each age the graphs plot the change in $80 \mathrm{~g} / \mathrm{d}$ portions compared with intake at 2 years of age. The graphs also show the increase or decrease in consumption of daily portions between adjacent ages. Both pieces of information thus describe the profile of consumption with increasing age. Fig. 4 shows the estimated cohort effects on FV intakes, that is, the increase or decrease in intakes compared with the youngest cohort. Estimates of the model regressions are presented in Table 1 and in the online Supplementary material.

\section{Total fruit and vegetable intake}

No differences were found in the change with age in total FV intake between boys and girls (Fig. 1), except the change at 21 years $(P=0.039$, table not shown). Results showed that children consumed less FV portions during adolescence: after increasing their intake from early childhood to the age of 7 years $(P=0.067$, boys, Table 1$)$, intakes had dropped by the age of 12 years $(P<0.001$, difference with respect to 7 years, boys, Table 1), and changed little during the teenage years. Although differences did not reach statistical significance, during the adolescent years, there was a trend in lower intakes of up to one portion compared with intakes at the age of 2 years (online Supplementary Table S1.3). Intakes appeared to recover from the age of 17 years to early adulthood, but this increase was not statistically significantly different from zero $(P=0 \cdot 1634$ between 17 and 23 years, boys). Trajectories of FV portions excluding the contribution to total intake from composite dishes were similar, except that the change in age during the young

5 The number of cohorts is given by the formula $C=A+T-1$; where $C$ is the number of cohorts, $A$ the number of age groups and $T$ the number of years ${ }^{(23)}$.

${ }^{6}$ This method was preferred over the nutrient density or the regressionadjustment approach given low correlations of FV intake and total energy intake $(r 0.03 \text { for fruit to } r 0.33 \text { for vegetables })^{(29)}$.

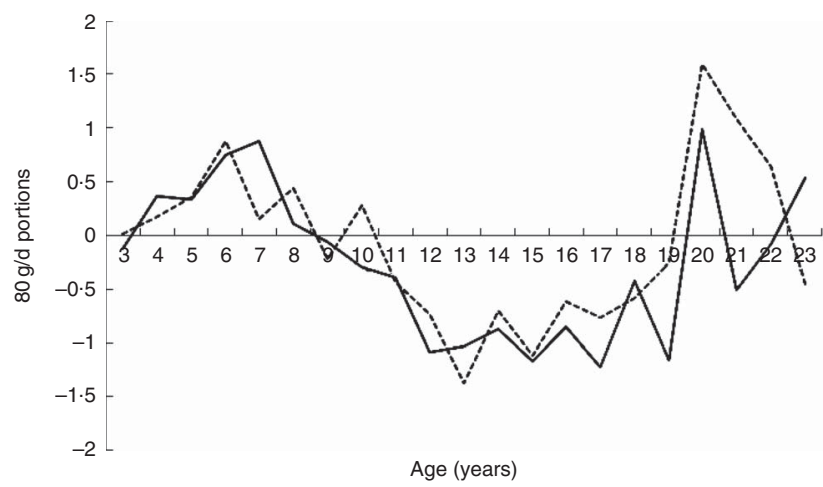

Fig. 1. Change with age of fruit and vegetables (FV) intake, boys and girls. At each age the graph indicates the average difference in the amount consumed compared with that of a 2-year old and the change in intake between adjacent ages. Change with age are the coefficients from the regressions of FV on age dummies, controlling for cohort effects, normalised year effects and total energy intake from food. Models by sex from the interaction effects between the age dummies and sex with the corresponding reference category for each model (boys and girls, respectively). Pooled National Diet and Nutrition Survey years 1-4 waves. FV intake including contribution from composite dishes. — , Total FV (including juice) portions, boys; -.-- , total FV (including juice) portions, girls.
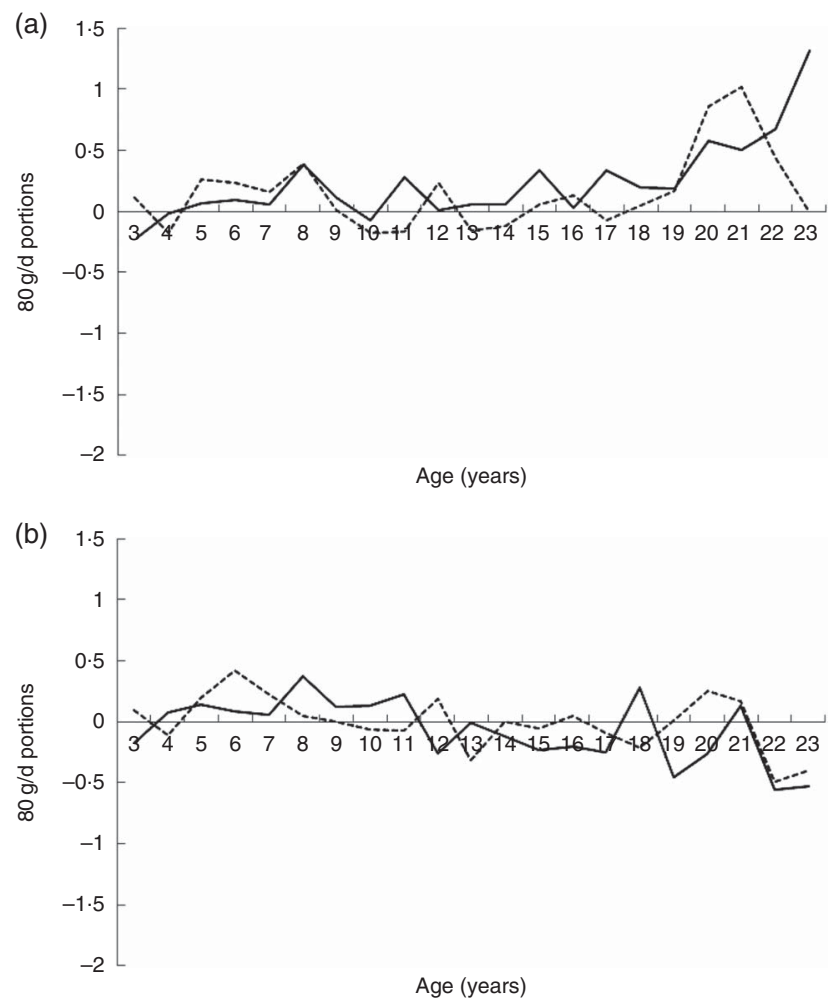

Fig. 2. Increase or decrease with age in vegetable intake, boys ( - ) and girls (- - - ): (a) including composite dishes; (b) excluding composite dishes. Vegetable portions included a maximum of $80 \mathrm{~g}$ per $\mathrm{d}$ of pulses and five times the intake of tomato purée. At each age the graph indicates the average difference in the amount consumed compared with that of a 2-year-old and the change in intake between adjacent ages. Changes with age are the coefficients from the regressions of vegetable intake on age dummies, controlling for cohort effects, normalised year effects and total energy intake from food. Models by sex from the interaction effects between the age dummies and sex with the corresponding reference category for each model (boys and girls, respectively). Pooled National Diet and Nutrition Survey year 1 to year 4 waves. 

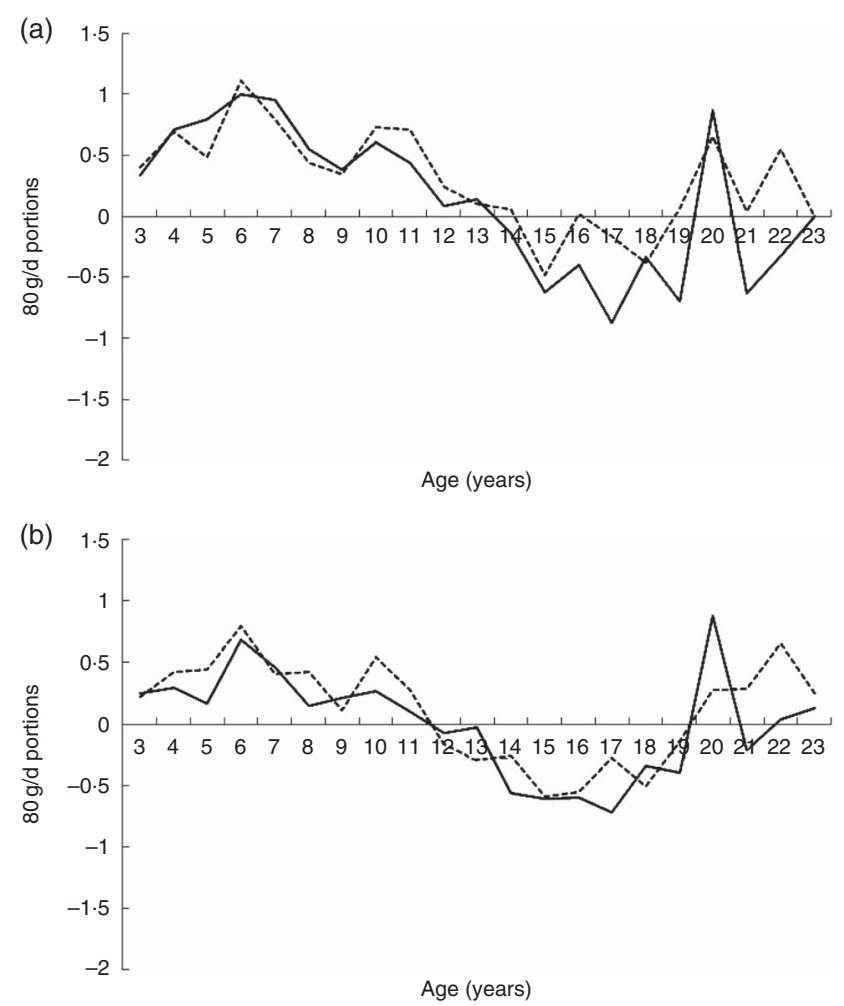

Fig. 3. Increase or decrease with age in fruit intake, boys $(-)$ and girls (---): (a) including fruit juice; (b) excluding fruit juice. Total fruit portions included a maximum of $150 \mathrm{~g} / \mathrm{d}$ of fruit juice and $160 \mathrm{~g} / \mathrm{d}$ of fruit smoothies, and three times the intake of dried fruits. At each age the graph indicates the average difference in the amount consumed compared with that of a 2-year-old and the change in intake between adjacent ages. Changes with age are the coefficients from the regressions of fruit intake on age dummies, controlling for cohort effects, normalised year effects and total energy intake from food. Models by sex from the interaction effects between the age dummies and sex with the corresponding reference category for each model (boys and girls, respectively). Pooled National Diet and Nutrition Survey year 1 to year 4 waves. Fruit intake including contribution from composite dishes. adulthood years presented a slower recovery from the drop during adolescence (online Supplementary Table S1.3, graph not shown).

\section{Vegetables intake}

Girls' change in vegetables intake with age was also not significantly different from that of boys, except at the age of 23 years $(P=0.026$, table not shown). For both groups, total vegetable intake changed very little, except after the age of 17 years, when intake showed growth, albeit not reaching statistical significance and being sustained only for boys ( $P=0.186$ for intake at 17 years compared with 23 years, boys, Table 1). Trends with age in vegetable portions excluding the contribution from composite dishes showed a similar pattern (Fig. 2), but without any positive change between the ages of 17 and 23 years $(P=0.532$, boys, Table 1$)$.

\section{Fruit intake}

As with total FV and with vegetables, girls' change in fruit intake differed little from boys', with exceptions at the age of $8(P=0.05$, fruit excluding juice, table not shown) and 17 years $(P=0 \cdot 039$, fruit including juice; $P=0.06$, fruit excluding juice), and with marginally significant differences at $19(P=0.065$, fruit including juice) and 22 years ( $P=0 \cdot 085$, fruit including juice). In contrast to vegetable intake, changes with age were observed for fruit and fruit juice intake (Fig. 3), reflecting the total FV age trends discussed above. Thus, after a brief period of growth until about the age of 7 years, children started eating less fruit portions as they grew older (differences between the ages of 7 and 12 years: $P=0 \cdot 059$, boys; $P=0.054$, girls, Table 1). From that point on, girls' intake did not change significantly during adolescence (difference between 12 and 17 years: fruit, $P=0.716$; fruit including juice, $P=0.358$ ), but the trajectory of boys showed further deterioration in fruit portions consumed with each passing year $(P=0 \cdot 013$,

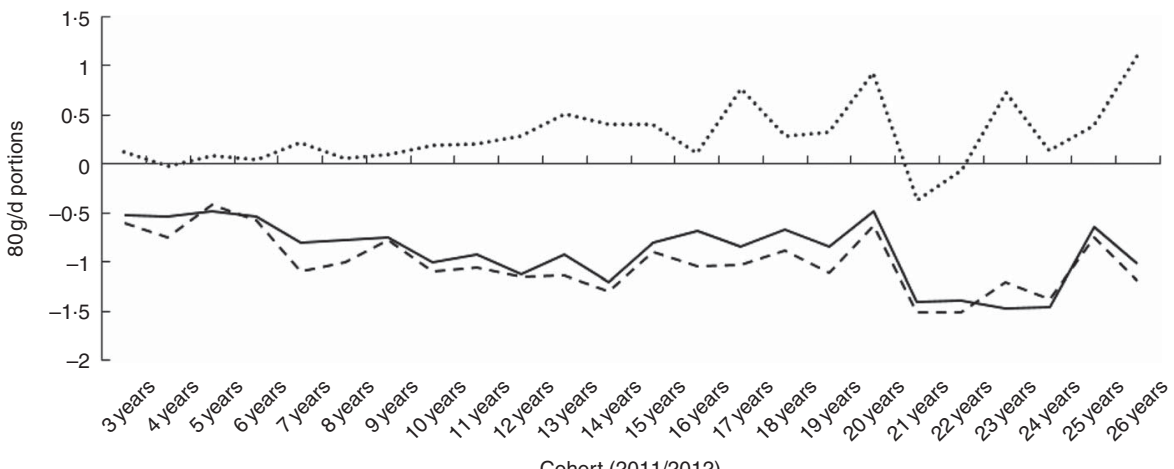

Fig. 4. Change in fruit and vegetables (FV) consumption from older to younger cohorts. Total fruit portions included a maximum of $150 \mathrm{~g} / \mathrm{d}$ of fruit juice and $160 \mathrm{~g} / \mathrm{d}$ of fruit smoothies, and three times the intake of dried fruits. Vegetable portions included a maximum of $80 \mathrm{~g} / \mathrm{d}$ of pulses and five times the intake of tomato purée. At each cohort the graph indicates the average difference in the amount consumed compared with the youngest cohort (children aged 2 years in 2011/2012), and the change in intake between contiguous cohorts. Change across cohorts are the coefficients from the regressions of FV on cohort effects, controlling for age effects, normalised year effects and total energy intake from food. Pooled National Diet and Nutrition Survey years $1-4$ waves. FV intake including contribution from composite dishes. ........, Vegetable portions, not from composite; - - - - , fruit (including juice) portions; $\_$, fruit (excluding juice) portions. 
Table 1. Tests of differences at selected ages in consumption of fruit and vegetables (FV) portions for males and females*

\begin{tabular}{|c|c|c|c|c|}
\hline \multirow[b]{2}{*}{ Age (years) } & \multicolumn{2}{|c|}{$\begin{array}{l}\text { Including composite } \\
\text { dishes }\end{array}$} & \multicolumn{2}{|c|}{$\begin{array}{c}\text { Excluding composite } \\
\text { dishes }\end{array}$} \\
\hline & Boys & Girls & Boys & Girls \\
\hline \multicolumn{5}{|c|}{ Total FV portions } \\
\hline$F_{1,105}$ & $\begin{array}{l}3.43 \\
0.067\end{array}$ & $\begin{array}{l}0.05 \\
0.822\end{array}$ & $\begin{array}{l}1.38 \\
0.242\end{array}$ & $\begin{array}{l}0.01 \\
0.936\end{array}$ \\
\hline \multicolumn{5}{|l|}{7 v. 12} \\
\hline $\begin{array}{l}F_{1,105} \\
P\end{array}$ & $\begin{array}{c}13 \cdot 38 \\
0.000\end{array}$ & $\begin{array}{l}1.76 \\
0.187\end{array}$ & $\begin{array}{l}9.46 \\
0.003\end{array}$ & $\begin{array}{l}0.72 \\
0.399\end{array}$ \\
\hline \multicolumn{5}{|l|}{12 v. 17} \\
\hline $\begin{array}{l}F_{1,105} \\
P\end{array}$ & $\begin{array}{l}0.07 \\
0.797\end{array}$ & $\begin{array}{l}<0.01 \\
0.955\end{array}$ & $\begin{array}{l}1.55 \\
0.216\end{array}$ & $\begin{array}{l}0.74 \\
0.393\end{array}$ \\
\hline \multicolumn{5}{|l|}{17 v. 23} \\
\hline $\begin{array}{l}F_{1,105} \\
P\end{array}$ & $\begin{array}{l}1.97 \\
0.163\end{array}$ & $\begin{array}{l}0.06 \\
0.815\end{array}$ & $\begin{array}{l}0.65 \\
0.423\end{array}$ & $\begin{array}{l}<0.01 \\
0.944\end{array}$ \\
\hline \multicolumn{5}{|c|}{ Vegetable portions } \\
\hline $\begin{array}{l}F_{1,105} \\
P\end{array}$ & $\begin{array}{l}1.56 \\
0.214\end{array}$ & $\begin{array}{l}0.05 \\
0.823\end{array}$ & $\begin{array}{l}3.11 \\
0.081\end{array}$ & $\begin{array}{l}1 \cdot 10 \\
0.296\end{array}$ \\
\hline \multicolumn{5}{|l|}{7 v. 12} \\
\hline $\begin{array}{l}F_{1,105} \\
P\end{array}$ & $\begin{array}{l}0.04 \\
0.834\end{array}$ & $\begin{array}{l}0.04 \\
0.843\end{array}$ & $\begin{array}{l}2 \cdot 65 \\
0.106\end{array}$ & $\begin{array}{l}0.02 \\
0.888\end{array}$ \\
\hline \multicolumn{5}{|l|}{12 v. 17} \\
\hline $\begin{array}{l}F_{1,105} \\
P\end{array}$ & $\begin{array}{l}1.04 \\
0.310\end{array}$ & $\begin{array}{l}0.58 \\
0.448\end{array}$ & $\begin{array}{c}<0.01 \\
0.971\end{array}$ & $\begin{array}{l}0.77 \\
0.383\end{array}$ \\
\hline \multicolumn{5}{|l|}{17 v. 23} \\
\hline$F_{1,105}$ & 1.77 & 0.01 & 0.39 & 0.45 \\
\hline$P$ & 0.186 & 0.924 & 0.532 & 0.504 \\
\hline \multicolumn{5}{|c|}{ Fruit portions $†$} \\
\hline$F_{1,105}$ & 1.59 & $1 \cdot 23$ & 1.85 & 1.00 \\
\hline$P$ & 0.211 & 0.269 & 0.177 & 0.321 \\
\hline \multicolumn{5}{|l|}{7 v. 12} \\
\hline$F_{1,105}$ & 2.25 & 1.74 & $3 \cdot 2$ & 1.94 \\
\hline$P$ & 0.137 & 0.191 & 0.076 & 0.167 \\
\hline \multicolumn{5}{|l|}{12 v. 17} \\
\hline$F_{1,105}$ & 4.88 & 0.85 & $6 \cdot 12$ & 0.90 \\
\hline$P$ & 0.029 & 0.358 & 0.015 & 0.345 \\
\hline \multicolumn{5}{|l|}{17 v. 23} \\
\hline$F_{1,105}$ & 0.81 & 0.03 & $1 \cdot 26$ & 0.04 \\
\hline$P$ & 0.371 & 0.868 & 0.265 & 0.840 \\
\hline \multicolumn{5}{|c|}{ Fruit portions $\ddagger$} \\
\hline \multicolumn{5}{|l|}{3 v. 7} \\
\hline$F_{1,105}$ & 0.29 & 0.29 & $0 \cdot 16$ & $<0.01$ \\
\hline$P$ & 0.590 & 0.594 & 0.686 & 0.967 \\
\hline \multicolumn{5}{|l|}{7 v. 12} \\
\hline$F_{1,105}$ & 3.65 & 3.79 & $4 \cdot 17$ & $2 \cdot 89$ \\
\hline$P$ & 0.059 & 0.054 & 0.044 & 0.092 \\
\hline \multicolumn{5}{|l|}{12 v. 17} \\
\hline$F_{1,105}$ & $6 \cdot 45$ & 0.13 & 9.54 & 0.68 \\
\hline$P$ & 0.013 & 0.716 & 0.003 & 0.412 \\
\hline \multicolumn{5}{|l|}{17 v. 23} \\
\hline$F_{1,105}$ & 1.73 & 0.53 & 1.45 & 0.47 \\
\hline$P$ & 0.191 & 0.470 & 0.232 & 0.495 \\
\hline
\end{tabular}

* Age coefficients from the regressions of FV on age dummies, controlling for cohor effects, normalised year effects and total energy intake from food. Models with interaction effects between the age dummies and sex with the corresponding reference category for each model (boys and girls, respectively). $P$ value from Wald's $F$ tests for the equality of the age coefficient estimated from the regressions of FV intakes on age. Data from years 1 to 4 of the Rolling Programme of the National Diet and Nutrition Survey.

† Fruit including fruit juice.

‡ Fruit excluding fruit juice.

fruit including juice $P=0.029$, Table 1 ). Notably, there was no real improvement in the intake trajectory after the age of 17 years for either boys or girls (Table 1). Trends were similar when considering fruit intake excluding composite dishes: by the age of 17 years, boys were consuming-0.93 ( $P=0.037$, online Supplementary Table S1.3) portions less than when they were 2 years old, and girls were consuming $-0.50(P=0.254)$ portions less. During young adulthood, girls' intake recovered slightly, but this change did not reach statistical significance.

\section{Fruit and vegetables intakes across cohorts}

Looking at change in FV intake across cohorts (boys and girls combined), results showed variability about the difference across cohorts, but generally, the younger cohorts were consuming more fruit and fruit juice than the older cohorts (but not the oldest cohorts). At the same time, there were no differences between cohorts for vegetable intake. Results were comparable for FV intake from composite dishes (online Supplementary Table S1.4).

\section{Discussion}

The present study explored the trajectory of FV consumption from childhood to young adulthood, adding to a greater understanding of how consumption of these healthy foods can change during youth. The methods applied controlled for year and cohort effects in order to extract the effect of age on intake while allowing for the use of a large national data set with information on toddlers and up to 23-year-olds. Results showed that overall FV consumption started to decrease much earlier than the adolescent years, this trend being driven mainly by drops in fruit intake. Moreover, there was a trend for changes in intake during adolescence of up to a portion less of FV compared with young childhood for both boys and girls, with unclear indication of recovery in intakes during early adulthood. The importance of these trends on children's healthy eating is further highlighted in the context of the intake levels of typical 2-yearolds. In the last wave of the NDNS (2011/2012), the median vegetable intake - including composite dishes - of boys was 0.9 portions/d (approximately $72 \mathrm{~g} / \mathrm{d}$ ) and 1.3 portions/d for girls $(100 \mathrm{~g} / \mathrm{d})$, and median total intake of fruit was 1.9 portions $/ \mathrm{d}$ $(153 \mathrm{~g} / \mathrm{d})$ for boys and two portions/d for girls $(160 \mathrm{~g} / \mathrm{d})$.

The results for change in fruit intake with age were in line with findings from the studies by Larson et al. ${ }^{(12)}$ and Demory-Luce et $a l^{(13)}$, suggesting common drivers of intakes in these two samples. At the same time, in contrast with the decrease noted in Larson et al., vegetable consumption changed little during childhood and adolescence. This trajectory continued into young adulthood when looking only at the data excluding composite dishes, but even when including vegetable intake from composite dishes, there was little evidence that vegetable consumption increased in young adulthood, presenting a difference to the growth reported in Demory-Luce et al. ${ }^{(13)}$. Changes in the level of support for FV intake and the greater freedom in food choice exercised by children as they grow older may explain the deterioration in fruit consumption with age. The stark differences between fruit and vegetables consumption may be because vegetables are typically served as part of main meals, and therefore less susceptible to 'not being eaten' compared with fruit.

Interestingly, the growth trends found for FV consumption were broadly similar for boys and girls during childhood 
and adolescence. This may be reflecting shared influences on changes in intake by age across both groups. Males and females did not differ in their vegetable intake in young adulthood, but women appeared to be consuming more fruit than men thanks to the contribution of fruit juice. Both potentially explaining this difference and presenting the challenge of improving males' total fruit consumption may be cultural barriers faced by boys and men for healthy eating. For example, previous research has identified negative perceptions among young men of fruit juices, and of fruit more generally, as being feminine foods ${ }^{(33,34)}$.

The trends by cohort indicated that the younger cohorts were eating significantly more fruit than the older cohorts. Possible explanations for the findings include the English School Fruit and Vegetable Scheme introduced in 2004, which increases the daily availability of FV during school-term time to children between 4 and 6 years attending state schools ${ }^{(7)}$; the compulsory nutrient-based standards imposed in primary schools in 2008 and the 2003 launch of the national '5-a-Day' information campaign; all of which may have put younger generations within more positive contexts for FV consumption, both through school environments and through raising parental awareness on the importance of FV intake. Results for fruits mirror the findings of Boddy et $a l{ }^{(35)}$, who detected an increase in fruit intake in large cohorts of 9-10 year-olds in Liverpool (UK), although the authors do not control for year effects. There were no significant differences between the younger and older cohorts for vegetable consumption. Children and young adults may be more willing or find it easier to increase their fruit and fruit juice consumption in order to improve their diets. These results, in conjunction with age trajectories, suggest that there is a need for greater efforts to improve vegetable consumption among initiatives to raise young people's FV consumption.

The differences with age in FV intake described in this study are generalisable to the UK child population because they represent changes with children's development after controlling for time and cohort differences. However, a number of limitations to the study are of note. Change in intake was explored in terms of daily $80 \mathrm{~g}$ portions, which refer to daily portion recommendations for adults and children older than 11 years ${ }^{(36)}$, as currently there are no child-specific portion size recommendations in place in the UK. However, the derived portions were not used to discuss adequacy of intake in young age groups, solely to depict change with age. Sensitivity analyses using data in grams ${ }^{7}$ showed that for both vegetable and fruit (excluding juice) portions, the age trends in grams and in portions were identical and data in portions represented just another way of depicting change with age. When including fruit juice, age trends in grams and in portions were very similar, with only sharper increases in total fruit intake at the ages of 7 and 10-12 years (results not shown). Sample sizes for the cohort estimates were relatively small because of the NDNS sample sizes for the age groups of interest, introducing less precision in the cohort-year cell means. The use of robust standard errors given the estimated nature of the dependent variable partly accounted for this greater

${ }^{7}$ Constraining for maximum amounts of fruit juice, smoothies and pulses, and multipliying the amount of dried fruit and tomato purée by the respective factors. uncertainty, yet the large standard errors impose cautious interpretations in some cases, particularly for the young adulthood years. The size of the sample may also have contributed to the more accentuated shifts in intake between ages, depicted graphically in Fig. 1 and 3. Statistical tests of significance were carried out to check the relevance of upward or downward shifts between ages to avoid over-interpreting results. The age at which children acquire experiences with food may be important to the preferences and eating habits they form ${ }^{(37)}$, but the simplifying assumption was made that the developmental trajectory would not change from generation to generation (absence of interactions). This assumption is commonly applied for studies covering just a few years ${ }^{(15,17,23)}$, as it is expected that generational change does not occur over short periods of time. Finally, the dietary assessment method of the NDNS was 4-d unweighted food records. Although this method is less burdensome on participants, therefore improving compliance, reporting of portion-sizes is subject to imprecisions that can induce upward or downward biases in intake estimates, such as in the case of fibre and energy intake, respectively ${ }^{(38)}$. Moreover, data collection for the NDNS took place across all months of the year to control for seasonality in food intake, but in the final pooled sample there was a slight over-representation of weekend days ${ }^{(28)}$, possibly resulting in lower estimated intakes of $\mathrm{FV}$ because diets tend to be less healthy during these days.

\section{Acknowledgements}

The authors are grateful to Suzana Al Moosawi for valuable help in preparing the data.

This work was supported by a University of Reading and a UK Food Standards Agency doctoral studentship (grant no. PG1015) to V. A. under the supervision of L. T. B., O. B. K. and W. B. T. The sponsor had no role in the study design, in the analysis and interpretation of findings or in the decision to submit the manuscript for publication.

V. A. reviewed the literature, prepared and analysed the data and wrote the first draft. L. T. B., O. B. K. and W. B. T. provided conceptual contributions and statistical advice. All authors shared in the writing of the paper.

This article does not contain any studies with human participants performed by any of the authors.

The authors declare that there are no conflicts of interest.

\section{Supplementary material}

For supplementary material/s referred to in this article, please visit https://doi.org/10.1017/S0007114517000599

\section{References}

1. Prynne CJ, Mishra GD, O'Connell MA, et al. (2006) Fruit and vegetable intakes and bone mineral status: a crosssectional study in 5 age and sex cohorts. Am J Clin Nutr 83, $1420-1428$.

2. Dauchet L, Amouyel P \& Dallongeville J (2009) Fruits, vegetables and coronary heart disease. Nat Rev Cardiol 6, 599-608.

3. Maynard M, Gunnell D, Emmett P, et al. (2003) Fruit, vegetables, and antioxidants in childhood and risk of adult cancer: the Boyd Orr cohort. J Epidemiol Community Health 57, 218-225. 
4. Bradlee ML, Singer MR, Qureshi MM, et al. (2010) Food group intake and central obesity among children and adolescents in the Third National Health and Nutrition Examination Survey (NHANES III). Public Health Nutr 13, 797-805.

5. Kim SA, Moore LV, Galuska D, et al. (2014) Vital signs: fruit and vegetable intake among children - United States, 2003-2010. MMWR Morb Mortal Wkly Rep 63, 671-676.

6. Yngve A, Wolf A, Poortvliet E, et al. (2005) Fruit and vegetable intake in a sample of 11-year-old children in 9 European countries: The Pro Children Cross-sectional Survey. Ann Nutr Metab 49, 236-245.

7. Jotangia D (2009) Chapter 14: children's fruit and vegetable consumption. In The Health Survey for England 2008 Volume 1: Physical Activity and Fitness, [R Craig, $\mathrm{J}$ Mindell and V Hirani, editors]. Leeds: The NHS Information Centre.

8. Holman DM \& White MC (2011) Dietary behaviors related to cancer prevention among pre-adolescents and adolescents: the gap between recommendations and reality. Nutr J 10, 1-8.

9. Cullen KW \& Zakeri I (2004) Fruits, vegetables, milk, and sweetened beverages consumption and access to a la carte/ snack bar meals at school. Am J Public Health 94, 463-467.

10. Hackett A, Gibbon M, Sratton G, et al. (2001) Dietary intake of 9-10-year-old and 11-12-year-old children in Liverpool. Public Health Nutr 5, 449-455.

11. Marks J, Barnett LM \& Allender S (2015) Change of school in early adolescence and adverse obesity-related dietary behavior: a longitudinal cohort study, Victoria, Australia, 2013-2014. Prev Chronic Dis 12, E145.

12. Larson NI, Neumark-Sztainer D, Hannan PJ, et al. (2007) Trends in adolescent fruit and vegetable consumption, 1999-2004: project EAT. Am J Prev Med 32, 147-150.

13. Demory-Luce D, Morales M, Nicklas T, et al. (2004) Changes in food group consumption patterns from childhood to young adulthood: the Bogalusa Heart Study. J Am Diet Assoc 104, 1684-1691.

14. Elinder L, Heinemans N, Zeebari Z, et al. (2014) Longitudinal changes in health behaviours and body weight among Swedish school children - associations with age, gender and parental education - the SCIP school cohort. BMC Public Health 14, 640.

15. Deaton A (2000) The Analysis of Household Surveys: a Microeconometric Approach to Development Policy, 3rd ed. Baltimore: The John Hopkins University Press.

16. Wooldridge JM (2006) Introductory Econometrics, A Modern Approach, 3rd ed. Mason, OH: Thomson South-Western.

17. Collins LM \& Sayer A (2000) Modeling growth and change processes. Design, measurement and analysis for research in social psychology. In Handbook of Research Methods in Social and Personality Psychology, pp. 478-495 [HT Reis and CM Judd, editors]. New York: Cambridge University Press.

18. Hill AJ (2002) Developmental issues in attitudes to food and diet. Proc Nutr Soc 61, 259-266.

19. Thomas J (1991) Food choices and preferences of schoolchildren. Proc Nutr Soc 50, 49-57.

20. Elder G Jr (1998) The life course as developmental theory. Child Dev 69, 1-12.
21. Masche JG \& van Dulmen MHM (2004) Advances in disentangling age, cohort, and time effects: no quadrature of the circle, but a help. Dev Rev 24, 322-342.

22. Attanasio OP \& Jappelli T (2001) Intertemporal choice and the cross-sectional variance of marginal utility. Rev Econ Stat $\mathbf{8 3}$, $14-27$.

23. McKenzie DJ (2006) Disentangling age, cohort and time effects in the additive model. Oxford B Econ Stat $\mathbf{6 8}$, 473-495.

24. Block SA, Keiss L \& Webb P (2002) Did Indonesia's crises of 1997/98 affect child nutrition? A cohort decomposition analysis of national nutrition surveillance data, Discussion Paper no. 5. Boston, MA: The Gerald J. and Dorothy R. Friedman School of Nutrition Science and Policy.

25. Browning M \& Deaton AS (1985) A profitable approach to labor supply and commodity demands over the life-cycle. Econometrica 53, 503-544.

26. Baranowski T, Cullen K, Basen-Engquist K, et al. (1997) Transitions out of high school: time of increased cancer risk? Prev Med 26, 694-703.

27. Scientific Advisory Committee on Nutrition (2011) Dietary Reference Values for Energy. London: The Stationery Office.

28. Nelson MC, Story M, Larson NI, et al. (2008) Emerging adulthood and college-aged youth: an overlooked age for weightrelated behavior change. Obesity (Silver Spring) 16, 2205-2211.

29. Willett WC, Howe GR \& Kushi LH (1997) Adjustment for total energy intake in epidemiologic studies. Am J Clin Nutr $\mathbf{6 5}$, 1220S-1228S.

30. Angrist JD \& Pischke J-S (2008) Mostly Harmless Econometrics: An Empiricist's Companion. Princeton, NJ: Princeton University Press.

31. Lewis JB \& Linzer DA (2005) Estimating regression models in which the dependent variable is based on estimates. Polit Anal 13, 345-364.

32. StataCorp (2013) Stata Statistical Software: Release.13. College Station, TX: StataCorp LP.

33. Krølner R, Rasmussen M, Brug J, et al. (2011) Determinants of fruit and vegetable consumption among children and adolescents: a review of the literature. Part II: qualitative studies. Int J Behav Nutr Phys Act 8, 112

34. Herbert G, Butler L, Kennedy O, et al. (2010) Young UK adults and the 5 A DAY campaign: perceived benefits and barriers of eating more fruits and vegetables. Int J Consum Stud 34, 657-664.

35. Boddy LM, Abayomi J, Johnson B, et al. (2014) Ten-year changes in positive and negative marker food, fruit, vegetables, and salad intake in 9-10 year olds: SportsLinx 2000-2001 to 2010-2011. J Hum Nutr Diet 27, 236-241.

36. Bates B, Lennox A, Prentice A, et al. (2014) National Diet and Nutrition Survey. Results from Years 1-4 (Combined) of the Rolling Programme (2008/2009-2011/12). London: Public Health England.

37. Skinner JD, Carruth BR, Bounds W, et al. (2002) Children's food preferences: a longitudinal analysis. J Am Diet Assoc 102, $1638-1647$.

38. Tabacchi G, Amodio E, Di Pasquale M, et al. (2014) Validation and reproducibility of dietary assessment methods in adolescents: a systematic literature review. Public Health Nutr 17, $2700-2714$ 